\title{
The practice of mindfulness
}

\section{From Buddhism to secular mainstream in a post-secular society}

\section{Introduction}

This paper will focus on the practice of mindfulness, which has migrated from being part of a religion, Buddhism, to being an integral part of Western psychology. Mindfulness is especially used in cognitive behavioural therapy (Plank 2011: 200), but also in, for example, dialectical behavioural therapy $(\mathrm{DBT})^{1}$ and acceptance and commitment therapy $(\mathrm{ACT})^{2}$. In Sweden several doctors, psychologists and psychiatrists use and recommend mindfulness for therapeutic purposes, and some, like Åsa Nilsonne, Ola Schenström and Anna Kåver, have written well-known books about the practice (see, e.g., Nilsonne 2009 and 2011, Schenström 2007, Kåver 2011). Mindfulness is used today in many segments of mainstream medical and therapeutic care.

Mindfulness is also used outside the mainstream medical and therapeutic sector, in the area of personal development or spirituality, as well as in more traditional Buddhist groups and innovative Buddhist groups such as vipassana groups. One example is the group formed by S. N. Goenka.

The purpose of this paper is to investigate the migration of mindfulness from a religious to a secular sphere, and to discuss whether mindfulness is a religious practice or not. I will also discuss whether 'religious' is a meaningful term in our contemporary society, and what the term 'post-secular' might mean. My main sources have been a PhD dissertation in the history of religion at Lund University by Katarina Plank (2011) as well as books written by

1 This therapy was developed by Marsha Linehan, originally intended to help people with borderline personality disorders, but has also been used for other kinds of problems (Plank 2011: 201).

2 ACT is developed by Steven Hayes, and the strategy here is to observe and accept the emotions (Plank 2011: 202). 
some of the medical doctors and psychiatrists who initiated the practice of mindfulness in the US and in Sweden.

The paper is structured so that I will first give a summary of the book Full Catastrophe Living (1990) by Jon Kabat-Zinn, the publication of which started the wave of using mindfulness for therapeutic purposes, and then I will relate some of the scientific studies conducted on the practice as presented in the popular books about mindfulness. After that I will discuss the historical background of mindfulness in Buddhism, and cultural and structural factors which may have been important for the rapid adoption of mindfulness into Western therapy. Finally I will discuss if and in what sense mindfulness could and should be related to Buddhism, religion and post-secularity.

\section{Jon Kabat-Zinn and mindfulness in a therapeutic context}

Jon Kabat-Zinn, a medical professor who wrote his $\mathrm{PhD}$ in molecular biology, published his popular book Full Catastrophe Living in 1990. Jon KabatZinn had a background in different Buddhist environments, having attended courses by Western vipassana teachers such as Jack Goldstein and Joseph Kornfield, but also by the Zen master Thich Nhat Hahn, as well as by different Tibetan Buddhist teachers. From this experience, he attempted to isolate a technique, mindfulness, from its Buddhist context (Plank 2011: 200-3). His own standpoint was that the technique derived from Buddhism, but was not part of Buddhism: the essence is universal, independent of any belief system or ideology and therefore accessible to anyone. Yet, he writes, it is no coincidence that mindfulness derives from Buddhism, as Buddhism has an overriding concern for the relief of suffering and the dispelling of illusions (Kabat-Zinn 2009: 12-13). At the University of Massachusetts Kabat-Zinn developed a programme to treat chronic pain and stress related diseases called Mindfulness Based Stress Reduction, MBSR. It consists of different mindfulness and relaxation practices, as well as practices for cultivating a mindful attitude in daily life. It contains a programme of 8-10 weeks, where the participants meet once a week and receive instructions and practices, together with discussions about stress and coping strategies. The participants are expected to practice at home (Plank 2011: 200-1). Patients referred to this clinic may suffer from, for example, heart disease, cancer, lung disease, hypertension, headaches, chronic pain problems, sleep disorders, panic attacks, stress-related digestive problems and skin problems (Kabat-Zinn 2009: 7). Kabat-Zinn identifies his stress reduction programme as part of a new 
branch of medicine known as behavioural medicine, which is based on the conviction that mental and emotional factors may have a significant effect on physical health and the capacity to recover from illness and injury (p. 1).

The book Full Catastrophe Living is divided into five parts. The first part describes the techniques of mindfulness used in the stress reduction programme and relates some experiences by people who have followed it. The techniques encompass sitting meditation, the practice of non-doing and presence; attention on the breath; the famous 'raisin experience', which involves eating a raisin with full attention; the body scan technique, which is a relaxation technique aimed at 'being in your body'; yoga postures; walking meditation, and attentiveness in daily life. The second part presents research findings as a background for understanding how the practice of mindfulness could be related to physical and mental health, and also presents a holistic way, or a way of 'interconnectedness', of conceiving the human being and life as a whole. In this section the loving kindness meditation-with roots in traditional Buddhism-is also presented. One chapter presents evidence suggesting that beliefs, attitudes, thoughts, and emotions can both harm and heal the human being. The third part discusses stress-which is said to be the popular name for the 'full catastrophe'-and the fourth part suggests how to utilise mindfulness in specific areas; for example what to do with physical and emotional pain, as well as with fear, anxiety and sleep problems. The fifth part gives practical suggestions for maintaining and using mindfulness in all aspects of life. It is emphasised that it is important to find time for formal practice every day, but that also the informal ways of practising are important (Kabat-Zinn 2009).

\section{What is mindfulness according to therapeutic sources?}

Plank refers to Christopher Germer (2005) in identifying three key concepts in therapeutic mindfulness: 1) awareness, 2) of the present experience, 3) with acceptance (Plank 2011: 204). Kabat-Zinn emphasises paying attention to the present moment, including the full spectrum of our experiences, the good, the bad and the ugly, to be at home in one's own skin (2009: xxviiixxix). Different kinds of stress-or pain-cannot be avoided: they have to be faced. Escape and avoidance is not a way to solution (pp. 2-3). The full catastrophe of life-the enormity of our life experience-should, according to Kabat-Zinn, be embraced, not resisted. Everything in life is temporary and constantly changing (p. 6). There is a way to learn to allow oneself to be in the moment with things exactly as they are, without trying to change anything (p. 20). Kabat-Zinn emphasises the importance of the non-judging attitude, 
to be an impartial witness to the experience. You have to become aware of the constant stream of judging thoughts and reactions to inner and outer experiences that we are normally caught up in, and learn to step back from it (p. 33). Acceptance means seeing things as they actually are in the present moment. If you have a headache-accept it (p. 38). We should also learn to let go of thoughts and feelings that the mind seems to want to hold on to (p. 39). Kabat-Zinn emphasises the importance of practising every day (p. 141) - which differs from many other therapeutic contexts, where mindfulness may be practised only occasionally.

The Swedish psychiatrist Åsa Nilsonne is quite similar to Kabat-Zinn in her writings-with different chapters in one of her books dealing with, for example, thoughts, emotions, body, sleep, and people-and emphasises the effect of mindfulness in increasing the quality of life, both for people trying to make an ordinary life work, and for people with psychiatric problems (Nilsonne 2011: 10-13). Nilsonne sums up the definition of therapeutic mindfulness as an awareness of the present moment (p. 14), with four corner stones; observation, description, non-judgement, and participation (p. 22).

\section{Mindfulness as an evidence-based practice}

There have been a lot of studies on mindfulness, and there is a lot of evidence that there are effects of the practice on many different kinds of problems. This means that the practice of mindfulness has been legitimated by one of the strongest institutions for legitimation in Western society: science.

I will give a few examples of some of the studies, as they are presented in the popular books about mindfulness. The Swedish doctor Ola Schenström refers, for example, to studies of Kabat-Zinn's MBSR course, which show a significant reduction of symptoms such as pain and sleep problems. The physical symptoms decreased, according to the studies Schenström refers to, by on average 30-35 percent, and mental symptoms like anxiety and depression by 40-50 percent. Most of the patients declared improved life quality after the course. Schenström also refers to studies showing a lot of positive results from the MBSR course, including lower blood pressure, stress reduction, less pain and fewer mental symptoms from chronic pain, the improvement of chronic headaches, less pain and depression related to fibromyalgia, less anxiety and improved sleep for cancer patients, less inflammation and fewer mental symptoms for patients with rheumatic diseases, less stress and fewer symptoms for patients with multiple sclerosis, and fewer problems for patients with irritatable bowels (Schenström 2007: 71-2). Schenström also refers to other studies where DBT-in which mindfulness is an integral part-has been suc- 
cessful in treating young patients with borderline personality disorders and a self destructive behaviour, as well as studies showing that a combination of cognitive therapy and mindfulness has reduced relapses into depression to half in treated patients who have had three or more depressions (2007: 73-4). Nilsonne also refers to several studies on mindfulness in different areas, some of them apparently the same as the ones Schenström refers to (2009: 88-9).

There are also a lot of recent popular books on how to use mindfulness for different kinds of problems. Examples are the use of mindfulness in treating Asperger's syndrome (Mitchell 2009), use of mindfulness in depression (Williams 2008), mindfulness in teaching (Terjestam 2010), or how to give birth with mindfulness (Engström 2010).

\section{Mindfulness-the historic Buddhist background}

\section{The origin of mindfulness in Buddhism}

Mindfulness is the English translation of the Pali concept sati, which is the language of the early Buddhist scriptures. Sati is also the seventh limb in the eightfold path, translated as 'right mindfulness'. Plank writes that sati is a complex and central concept in the Theravada meditation practice, which encompasses several different aspects and therefore is very difficult to translate. Sati is referred to, allegedly, by the Buddha in Satipatthana Sutta and Mahasatipatthana Sutta, and is there claimed to be the only way of achieving the supreme goal, nibbana. Plank writes that the meditation process intends to develop a realisation of the fundamental conditions of existence, and that therefore the term vipassana (insight, realisation) is sometimes used when satipatthana (foundation of mindfulness) is referred to (Plank 2011: 188-90). According to Plank, the Theravada scripture Visuddhimagga differs between two main kinds of meditative orientations: concentration (samatha) and insight (vipassana) (2011: 39). The purpose of vipassana is to provide realisation, or insight into the fundamental conditions of existence, an experiencebased understanding of how existence is in continuous change (anicca), how this instability has no permanence (anatta) and how this results in dissatisfaction $(d u k k h a)$. The purpose of the meditation is to transcend the self conception by seeing through its illusory solidity. It is used in both Theravada and Mahayana Buddhism (Plank 2011: 42). According to Plank, vipassana meditation is based on interpretations of Satipatthana Sutta, and vipassana is synonymous with satipatthana (2011:38). 
Plank describes and discusses sati as a much more complex process than being 'just mindfulness' as in the contemporary therapeutic understanding, and claims that this is a simplification on several levels. In the Buddhist context sati is an important aspect of developing bodhi (awakening) and the final liberation (nibbana). Different frames of mind should, in traditional Buddhism, according to Plank not only be accepted-as in therapeutic mindfulness-but also seen and understood, and be replaced with more constructive ones. Sati in traditional Buddhism also has an important ethical dimension (Plank 2011: 188-98).

\section{Modern Buddhism and Western Buddhism}

Vipassana is the form of meditation which has spread most outside the Theravadan countries, and which has also been subjected to change by Western meditation teachers. One example is the movement started by S. N. Goenka, who started to teach vipassana in India at the end of the $1960 \mathrm{~s}$ (Plank 2011: 110).

Buddhism had, however, been subject to change and modernisation in the traditionally Buddhist countries before that. The renewal of vipassana came from Burma, where it became a mass movement for laymen during the twentieth century, following Buddhist reform movements in the nineteenth century all over Asia. The Buddhist revival was a response to the colonial powers, and a way to confirm national identities (Plank 2011: 54-60). The wisdom of the Buddha and of enlightenment was in several ways democratised (Plank 2011: 64). Central to this was the new Buddhist institution for laymen: the meditation centre, often situated in an urban context (Plank 2011: 38).

These central characteristics of modernised Buddhism - the focus on laymen, meditation, and the urban meditation centres-were also important in the Buddhist orientations which migrated to the West from the nineteenth century onwards.

\section{Western receptiveness: cultural and structural factors}

Katarina Plank (2011: 144-8) describes how Buddhism in different forms slowly migrated into Western cultures after initial contacts made during the sixteenth century. Buddhist texts were first translated into Western languages during the nineteenth century, and thus reached the broader public of the West at that time.

At the beginning of the twentieth century the first Europeans travelled to Asia to be ordinated as Buddhist monks, marking another stage at which Europeans became religious specialists and teachers of an Eastern religion. 
Another institution, the Theosophical Society, founded in New York in 1875, came to be important for the spread of Buddhist-related teachings in the Western world, as well as contributing to create a new and positive image of Buddhism in the West. The purpose of theosophy was to find 'the essence of all religions', and in this mission it used elements from the Eastern religions, among them Buddhism.

Until the middle of the twentieth century Plank describes Theravadan groups as being dominant in the West, but after the Second World War also Mahayana groups, especially from the Zen traditions, started to spread. During the 1960 s Asian teachers began visiting the West in larger numbers, and more Westerners started to travel to the East to learn more about the Eastern spiritual traditions.

Plank concludes that today two main kinds of Buddhism may be conceived of in the West: diaspora Buddhism with Asian-born participants, and a convertite Buddhism with Western-born participants. She writes that there are often barriers between these two kinds of Buddhism, relating both to language and kinds of practices (Plank 2011: 144-8).

It is a well-known fact that Buddhism has attracted Westerners partly because of the relative ease with which Buddhist perspectives can be related to secular and psychological ones. Buddhism differs in many ways from Christianity, not requiring belief in a God or in theological doctrines. Buddhism also supplies possible atheist interpretations and many theoretical elements about how the human mind works, based on the universal human experience of suffering and the problem of impermanence. This makes it easy to relate Buddhist thought to psychological and therapeutic perspectives, thereby also finding legitimation in the branch of psychology in Western science (for a discussion of similarities and differences between Buddhist perspectives and psychological ones, see, e.g., Imamura 1998).

One important route for Buddhism into Western culture was via the Human Potential Movement, which started at the beginning of the 1960 s. The Human Potential Movement developed out of humanistic psychology, which emphasised a belief in a positive human potential, a holistic view of the human being, and a syncretism between science and religion, East and West. The Human Potential Movement was practice-oriented, and used many kinds of practices, both therapeutic ones and practices based in different religious traditions. Buddhist perspectives and practices, like different kinds of meditation and attention practices, thus found ways into the new human potential culture, which was, at least partly, a secular one (Anderson 2004). 
The 1960 s and 1970 s saw many imported and innovative new religious movements arising in the West, with both Eastern and Western roots. One of them was Transcendental Meditation, which came to the West from India. With its roots in Hinduism-not Buddhism-Transcendental Meditation represents a parallel attempt to conceive of a meditative practice with Eastern religious roots as a scientific and therapeutic practice. Study of contemporary mindfulness therapy can provide something of a déjà $v u$ experience for someone studying new religious movements of the 1970s. Transcendental Meditation still exists in different countries all over the world, but today operates in a much more low key mode than during the heydays of the 1970s. A quick look at their web page today demonstrates many similarities with contemporary mindfulness. It is said there that the effects of TM have been proved by more than 600 scientific studies in more than 200 research institutes and universities in about 30 countries all over the world. The effects found include, for example, improved intelligence, better memory, increased creativity, decreasing high blood pressure, improved sleep, improved relations to others, less stress, and increased self confidence (http://tm-meditation.se, accessed on 20 November 2011).

Transcendental Meditation, however, never reached the mainstream in the way that mindfulness has done today. One reason for this may be the different kinds of leading figures in the two movements. In the case of TM, Maharishi Mahesh Yogi gave the impression of being quite a traditional Indian guru, with long hair and beard and Indian robes. Jon Kabat-Zinn, on the other hand, is a Western medical doctor and a professor, working in the academic environment. Besides, TM had some features which could be interpreted as Hindu or mystical, like the mantras or the initiation ceremony, and also later developments like the TM Sidhi programme (Frisk 1993: 163). Mindfulness, on the other hand, is explained as simply 'paying attention', which seems more secular and is easier to see through purely psychological lenses.

However, this is only part of the explanation for the success of mindfulness in the secular mainstream of contemporary Western society. There has also been a long work of preparation since the 1960s, which has resulted in a cultural adaptation and habituation to Eastern thought and practices. The ground was prepared for Jon Kabat-Zinn in the 1990s in another way than it was for Maharishi Mahesh Yogi two decades before.

Although in one way Jon Kabat-Zinn may talk about mindfulness in secular terms, he does not hide the fact of the Buddhist connections, nor does he refrain from practices such as the traditional Buddhist loving kindness meditation. Åsa Nilsonne also writes about Buddhism in positive terms, and ex- 
plains, in a popular way, how mindfulness relates to Buddhism. Buddhism is thus conceived of in a positive way by several mindfulness therapists. It could even be that the conceived relation to Buddhism might increase the attractiveness of mindfulness for some people. It would be interesting to ask the question as to whether the same practice with another more secular name, such as, for instance, 'attentional control training', would have become so popular. The relation to Buddhist traditions may give a scent and atmosphere around the practice of mindfulness, which may increase the sense of meaning, identity, and connection to a tradition, thereby also influencing both the expectations and the experiences of the practice in a positive way.

In spring 2011 I made telephone calls to some of the mainstream therapists working with mindfulness in Dalarna, Sweden, to ask about how they used mindfulness. ${ }^{3}$ Some of them asked me what I meant by mindfulness. Questioned about what they meant by that question they then replied that they knew of some therapists using some kind of relaxation as part of therapy and calling it mindfulness although it was not mindfulness in a strict sense. This indicates that 'mindfulness' may be an attractive catch-word, being used also outside of 'traditional' therapeutic mindfulness practices. If the term mindfulness is loosely used also, for example, for relaxation practices, this may indicate that there are even more simplifications in this area, altering the meaning of mindfulness and further increasing its distance from the traditional Buddhist context.

\section{But is mindfulness Buddhism?}

Everyone agrees about the historical connection between therapeutic mindfulness and Buddhism. Reading Jon Kabat-Zinn, his own relation to and inspiration from different schools of Buddhism is quite clear. Kabat-Zinn writes that it is no accident that mindfulness comes out of Buddhism, as Buddhism has as its overriding concerns the relief of suffering and the dispelling of illusions. However, he says that mindfulness is just a particular way of paying attention, and that its essence is universal, although it is most commonly taught and practised within the context of Buddhism (Kabat-Zinn 2009: 12-13). porary Religiosity in Local Expression and on New Arenas', financed by The Swedish Research Council between 2008-11, and on which I worked with Peter Åkerbäck, Stockholm University. 
Katarina Plank is one academic author who wants to emphasise the differences between Buddhist ways of mindfulness and therapeutic ones. She writes that the therapeutic practice of mindfulness involves both a decontextualisation, a recontextualisation, a reinterpretation and a simplification in a way that results in profound changes in the Buddhist practice of mindfulness. She uses the concept of 'mindfulness appropriators', to indicate people who use parts of Buddhist religious sources to strengthen their own views and to legitimate their own position, but without a genuine interest in the religion itself (Plank 2011: 209-10). She summarises the criticism from some Buddhist leading figures, pointing to the fact that mindfulness in therapeutic contexts is used for worldly purposes-which results in confirming and cementing the self-instead of realisation of the impermanence of the self and spiritual awakening (Plank 2011: 216-27). Thus Plank seems to indicate that mindfulness in a therapeutic sense distorts genuine Buddhism, and in reality could not be seen as part of the Buddhist tradition.

Anne-Christine Hornborg, another academic actor in the field, on the other hand, claims that no traditional religious practice, like mindfulness, could be reducible to a mere secular technique. She writes that if a Christian priest were to suggest offering intercessory prayer in a secular school, claiming that it is merely a secular technique, nearly everyone would say that this practice is impossible to detach from religion. This could, according to Hornborg, be compared to a therapeutic and secular use of mindfulness (Hornborg 2010). Thus Hornborg seems to argue for the 'religiousness' of therapeutic mindfulness, however not saying much about the 'Buddhistness' of the practice.

The last few years have seen an academic discussion on the concept of religion. There is an increasing awareness that the boundaries of what should be conceived of as religion or not are changeable, and may vary between different cultures, contexts and times. The concept and content of religion itself has a strong Western bias, and has been constructed to a great extent based on images and expressions of Christianity, especially the Protestant versions. In other cultures there are not always clear counterparts to 'religion' as it has been constructed and delimited in the West. Further, the borders of what has been conceived of as 'religion' have been constructed in ways to make some parts of the religious spectrum either excluded or devalued, based on Christian norms and values. There are normative distinctions between different religious behaviours and beliefs, creating more or less concealed definitions of what is a 'genuine' religion and what is not, thus marginalising and privileging different orientations of the religious spectrum. Terms like 'super- 
stition' or 'folk beliefs' are examples of cultural expressions often being conceived of as having less religious value and not being 'proper religion' (Asad 1993, Orsi 2005, McGuire 2008).

The conclusion of several academics in the field of religious studies is that the cultural expressions which in some contexts are defined as 'religious' apparently are just elements of cultural expressions as a whole, and that 'religion' has no special 'essence' about which it is possible to universally agree. To return to the question of whether mindfulness for therapeutic purposes is a religious practice or not, the definition of 'mindfulness' as religious or nonreligious totally becomes a question of how the concept of 'religion' is defined in the actual context. It may be 'in-defined' or 'out-defined' according to taste.

In addition to the problem of how to define 'religion', there is also a great individual span as to how to conceive of the practice of mindfulness, and what it might mean to the individual person. Individuals like Jon Kabat-Zinn and Åsa Nilsonne seem to interpret their own engagement with at least some kind of relationship to Buddhism, which may also-or may not-be the case with other therapists as well as their clients. Mindfulness as a practice may relate strongly, weakly or not at all to beliefs, emotional experiences, attitudes, values, inspiration, or sense of identity. Thus we may conclude that mindfulness as a therapeutic practice may, for some people, relate to some spectrum or some part of 'religion', but that this depends both on the individual and the definition of religion used.

It is important, however, to acknowledge the fact that the practice of mindfulness has deep roots in Buddhism, as well as the fact that the practice has changed (and become simplified) in the secular and therapeutic environments of the West-as all religious or religion-related elements change in new contexts. We have a phenomenon with religious roots in a new secular context, and it is quite natural that it also changes towards possible secular interpretations.

\section{Religion and post-secularity in the contemporary context}

Based on empirical material-interviews and field observations-from the recent research project 'The Meditating Dala Horse', one impression is that several people in the field neither use the concepts of 'religious' and 'nonreligious', nor seem to make this difference in their thinking and mental orientation. Many people seem to practice meditation, or some other practice, like for example, healing, Tarot, rebirthing sessions, yoga, or aroma massage, 
not wondering if this should be considered a religious or spiritual practice or not. It is just something they do, an activity which may or may not relate to different beliefs, feelings or values, or, in some cases, may be considered just a leisure activity for entertainment and fun. There seems to be a transition to an increasing importance of experiences, practices, and atmospheres, and less importance of beliefs and organisations. Different aspects of what it means to be human are investigated and experienced, without dividing these experiences into the 'religious' and 'secular'. In the same way, therapeutic mindfulness is probably in many cases just experienced, without any attempts to make a distinction as to whether the experience is related to religion or not. Siv Ellen Kraft writes that the market of new religiosity is characterised by 'hybrid products', by which she means that they are open to several interpretations, with or without religious references, and that at least some of the functions are secular. The spiritual part may be either completely or partly empty (Kraft 2011: 78).

Tentatively, this tendency not to distinguish between religion and nonreligion is one of the traits which characterises our contemporary society, and is what would make the notion of 'post-secularity' meaningful. Our culture is neither religious nor secular, as the question of what is religion or not has become meaningless. 'Religion' is a concept some people like to stamp on some cultural expressions, but the term is dependent on the kind of definition which is postulated, and does not answer to a difference many people today in reality make and use. If we need a term for this characteristic, 'post-secularity' may be one suggestion.

\section{Conclusion}

The practice of mindfulness has migrated from Buddhist contexts to Western therapeutic contexts, thereby going through changes and simplifications, making it potentially subject to both religious and secular interpretations, or being a 'hybrid product'. In this article, it has been suggested that the difference between 'religious' and 'secular' is losing meaning and importance in our contemporary society, and that it is precisely this element which characterises a 'post-secular' culture. Previously conceived of 'religious' elements are now spreading into many sectors of society, thereby changing, adapting, and losing aspects that used to characterise 'religion'. These practices may be individually interpreted and actively used as religious or not, depending on definition and taste. Mindfulness is one example of such practices, but there are 


\section{LISELOTTE FRISK}

many more examples which are widely used in contemporary society which are finding their ways into mainstream. One example is yoga, which also has an Eastern religious background, is used in many mainstream contexts today, but may also be practised and used from many different perspectives. Other therapeutic practices, such as rebirthing, Gestalt therapy, or coaching, may or may not also include 'religious' elements. The definite point of this article, however, is that attempts at making this difference in our contemporary culture may have lost meaning, and that other terms than 'religion' may be more meaningful to use.

\section{References}

\section{Anderson, Walter Truett}

2004 The Upstart Spring: Esalen and the Human Potential Movement, the First Twenty Years. Lincoln, NE: iUniverse Inc.

\section{Asad, Talal}

1993 Genealogies of Religion: Discipline and Reasons of Power in Christianity and Islam. Baltimore: Johns Hopkins University Press.

\section{Engström, Maria}

2010 Förlossningsförberedelser för blivande föräldrar. Att föda med mindfulness. Stockholm: Gothia.

\section{Frisk, Liselotte}

1993 Nya religiösa rörelser $i$ Sverige. Relation till samhället/världen, anslutning och engagemang. Åbo: Åbo Akademi.

\section{Germer, Christopher}

2005 'Mindfulness: What is it? Why does it matter?' In: Christopher K. Germer, Ronald D. Siegel \& Paul R. Fultun (eds), Mindfulness and Psychotherapy. 3-27. New York: Guildford.

\section{Hornborg, Anne-Christine}

2010 'Designing rites to re-enchant secularized society: new varieties of spiritualized therapy in contemporary Sweden. Journal of Religion and Health 25.5.2010. DOI: 10.1007/s10943-010-9356-5.

\section{Imamura, Ryo}

1998 'Buddhist and Western psychotherapies: an Asian American perspective.' In: Charles S. Prebish \& Kenneth K. Tanaka (eds), The Faces of Buddhism in America. 228-37. Los Angeles, London: University of California Press.

\section{Kabat-Zinn, Jon}

2009 Full Catastrophe Living: Using the Wisdom of Your Body and Mind to Face Stress, Pain, and Illness. New York: Delta Trade Paperback. 


\section{Kåver, Anna}

2011 Den terapeutiska relationen i KBT. Stockholm: Natur \& Kultur.

Kraft, Siv Ellen

2011 Hva er nyreligiösitet? Oslo: Universitetsforlaget.

\section{McGuire, Meredith}

2008 Lived Religion: Faith and Practice in Everyday Life. New York: Oxford University Press.

\section{Mitchell, Chris}

2009 Asperger's Syndrome and Mindfulness: Taking Refuge in the Buddha. London: Jessica Kingsley Publishers.

\section{Nilsonne, Åsa}

2009 Mindfulness i hjärnan. Stockholm: Natur \& Kultur.

2011 Vem är det som bestämmer i ditt liv? Om mindfulness. Stockholm: Natur \& Kultur.

\section{Orsi, Robert}

2005 Between Heaven and Earth: The Religious Worlds People Make and the Schol-

\section{Plank, Katarina}

2011 Insikt och närvaro. Akademiska kontemplationer kring buddhism, meditation och mindfulness. Göteborg \& Stockholm: Makadam förlag.

\section{Schenström Ola}

2007 Mindfulness $i$ vardagen. Vägar till medveten närvaro. Stockholm: Viva.

\section{Terjestam, Yvonne}

2010 Mindfulness i skolan. Om hälsa och lärande bland barn och unga. Lund: Studentlitteratur.

Williams, J. Mark G.

2008 Mindfulness. En väg ur nedstämdhet. Stockholm: Natur \& Kultur. 